UDC 37

DOI: $10.24044 / \mathrm{sph} .2017 .3 .9$

\title{
EVALUATING STUDENT TEACHERS IN MICRO-TEACHING WITH ANALYSIS OF VIDEO RECORDING LESSON BY BORIS SOFTWARE AT VIETNAM NATIONAL UNIVERSITY
}

\author{
Ch. Pham Kim
}

\author{
Ph. D., Lecturer \\ Vietnam National University \\ Hanoi, Vietnam
}

\begin{abstract}
Micro-teaching is a teacher training technique, where teacher-educator andstudentteacher can review a video-recording of a teaching session to see what has worked and what can be improved from student teacher's teaching practices. Evaluation (including continuous feedback) is a critical component in teacher education, in general and teacher student development, in particular. Using BORIS software as a main analysis tool to support teaching assessment, the article presents the digital evaluation processthroughobservationteaching via video that recordthe full range ofactivities, actionsand behaviorsofteachersand studentsinteaching in all corners of classroom. With the lack of practicum time and other appropriate conditions of teacher training program in Viet Nam, the video recording lessonsand analysis tool can provide a simple/easy/saving way to help student teacher clearly see his/her advantages and what need to improve, as well as to be a successful teacher-educator in a shorter path. The pilot of this study is taken place in teaching the course "curriculum and teaching/learning methods of Physics subject" at Faculty of Teacher Education, University of Education, VNU. The research outcome is positive.
\end{abstract}

Keywords: micro-teaching; video analysis; behavior observation; BORIS.

\section{Introduction}

Micro-teaching is a form of instructional training, where small groups of peers can observe each other's teaching, provide feedback, and engage in discussion with the goal of improving one another's instructional abilities via video-recording. Evaluating teaching for student teachersare the assessments that supports learning is critical for pedagogical development. For effective evaluation and assessment, the teacher educators in the teacher education programs need to focus on providing accurate evidences of teaching practice and clearly analyze the ad- vantages and disadvantage for student teachers. Classroom observation is one of the better ways to give feedback that support teaching skill growth and development. In all education reforms, the learning standards (outcomes) that student are expected to meet is an important as a teaching/learning achievement. Engaging students in meaningful tasks, monitoring students' understanding, and using students' feedback to improve teaching are critical.

In the normal (or "traditional") way, direct observation or indirectly evaluation is method to determine the 
behavior in the classroom. The direct observation of teaching activities take place in the classroom by a number of different participants have created a lot disadvantages, such as: a lot of activities, actions, behavior of teachers and students need to observe are ignored or cannot observe in a continuous process. The evaluation and assessment are incorrect is obvious. Using of digital video capture, storage, and analysis technologies to improve the preparation and continued professional development of student teachers is a popular strategy in the world-wide teacher education programs at the present. The following part describea process to plan, capture, edit, analyze, and store video clips of student teachers at practice.

\section{Evaluating student teachers in} Micro-Teaching with analysis of video recording lesson

Microteaching provides an opportunity to develop student instructional skills in a positive, learner-centered environment. Classroomobservations are the most common source of evidence used inproviding feedback to teachers. Systematic classroom observation is a quantitative method of measuring classroom behaviors from observations that specifies both the events or behaviors that are to be observed and how they are to be recorded. Generally, the data that is collected from this procedure focuses on the frequency with which specific behaviors or types of behavior occurred in the classroom and measures their duration.
Observing teaching lesson provides data of real situations, the teaching methods, effective guidance of teachers, to encourage students to engage in active comparator, description, criticism this is an opportunity to analyze teaching from different perspectives. Teachers may add new insights in teaching through the experience of the challenges and identify new ideas for their practical activities [1].

Systematic classroom observation is a quantitative method of measuring classroom behaviors from direct observations that specifies both the events or behaviors that are to be observed and how they are to be recorded. Generally, the data that is collected from this procedure focuses on the frequency with which specific behaviors or types of behavior occurred in the classroom and measures their duration. There are several elements that are common to most observational systems, as below:

- a purpose for the observation.

- operational definitions of all the observed behaviors.

- training procedures for observers.

- a specific observational focus.

- a setting.

- a unit of time.

- an observation schedule.

- a method to record the data.

- a method to process and analyze data [2].

There are three broad domains of teaching practice that are linked to positive student outcomes: social/emotional support, 
organization/management support, and instructional support.

+ Social and Emotional Supports: As a behavioral setting, classrooms run on interactions between and among participants. The types of teaching practices that may be observed under this domain, include:

- Teachers and students are enthusiastic about learning and respectful of one another.

- Teachers consistently respond to students and are effective in addressing students' questions, concerns, and needs.

- Teachers who value student perspectives provide opportunities for students to make decisions and assume leadership roles.

\section{$+\quad$ Organizational}

Management Supports: In the education literature focused on teaching and teacher training, perhaps no other aspect of classroom practice receives as much attention as classroom management and organization. The types of teaching practices that contribute to effective management/organization

include:behavior

banagement, productivity, strategies for Engaging Students, strategies that foster knowledge of procedures and Skills.

\section{$+\quad$ Instructional Supports:} Instructional methods have been put in the spotlight in recent years as more emphasis has been placed on the translation of cognitive science, learning, and developmental research to educational environments. It may be important to differentiate between general and content-specific instructional supports $[3 ; 4]$.

Through video observations can assess the performance of teachers, students' learning process. The assessment tools such as: observation and monitoring; assess learning progress (individual, group, teacher); comments from members.

Digital video can serve as a powerful tool to analyze student teaching practice. They will have an opportunity to review the videotaped recordings as a group, and provide further comments. It can help to see and hear how they work is perceived by others, and enable faculty to provide targeted feedback based on close analysis.

2. Analysis of video recording lessonwith analytic software

Technological advances are pushing the use of more powerful video. Increasingly, organizations in the world are developing analytical tools make the process of watching videos, analyzing and sharing video easier for teachers. Video analysis tool is emerging as a tool to facilitate access to teacher evaluation teaching. Therefore, there has been an increase in studies focusing on the benefits of using video to evaluate teaching [5].

Using video combined with video analytic software provides many benefits: Help can be observed several times, using the software recorded observations, descriptions of variables, the number of events, action is observed. Many people can observe a video as the basis for making the overall analysis. Using multiple cameras 
can allow recognition of different aspects of the class room. The uses of video to help observe the details, many times, multidimensional analysis, at anytime, anywhere... student can analyses their own practices, share their practices with other or review discussions with colleagues.

Evaluate teaching can base on the following five steps:

+ Step 1. Identify the purpose of evaluation. Defining the purpose of evaluating is very important in building behavioral description. Evaluation purposes, research questions must be consistent with the ability to provide information through video observation.

+ Step 2. Build behavioral description (ethogram). Following assessment aims to determine the types of behavior, information encoded into qualitative variables or quantitativebased encryption system.

+ Step 3: Develop evaluation criteria. The observer should have described the evaluation criteria and made in the grading criteria table (rubric). One can put the score for that level to assess quantitatively the need to define variables. The construction of the rubric is not only descriptive of the border but also creating unity between the people involved evaluation of teaching hours.

+ Step 4. Encode the video. Perform teaching hours of video, can watch over and over again recorded the information on the video by the observation sheets. Could use some video analysis software to support this process.
+ Step 5. Data analysis. The information recorded from the observation sheets, the data can be analyzed results of comparisons evaluated from a video watcher, or comparable teaching hours. If using video analysis software to encode the video, it can export tabular data to Excel or switch to SPSS software to aggregate data analysis will show results quickly and accurately.

\section{Process analysis software video on BORIS \\ BORIS (Behavioral Observation} Research Interactive Software) is software that analyzes the behavior such as behavior of animals, humans ... are recorded on digital video files (files like mp4, wmv, mpg ...)... (The software is free to use, can be downloaded free from the internet at the address http://www.boris.unito.it/).

Use BORIS analysis of the video file to the components:

+ File video recordinglesson.

+ Project file:describe in detail the acts, events and attributes of the variables used to encrypt want.

BORIS software analyzes video files by marking the encoded video and events. There are two types of behavior State, called the turnaround time and time Point called variables. The variables permitted range of values calculated interval, with variations for the location not only worth the time spent value time in the position marked.

After run the BORIS software, should produce a list of behaviors, open the video file turns teaching 
hours. BORIS screen appears as Fig- ure 1.

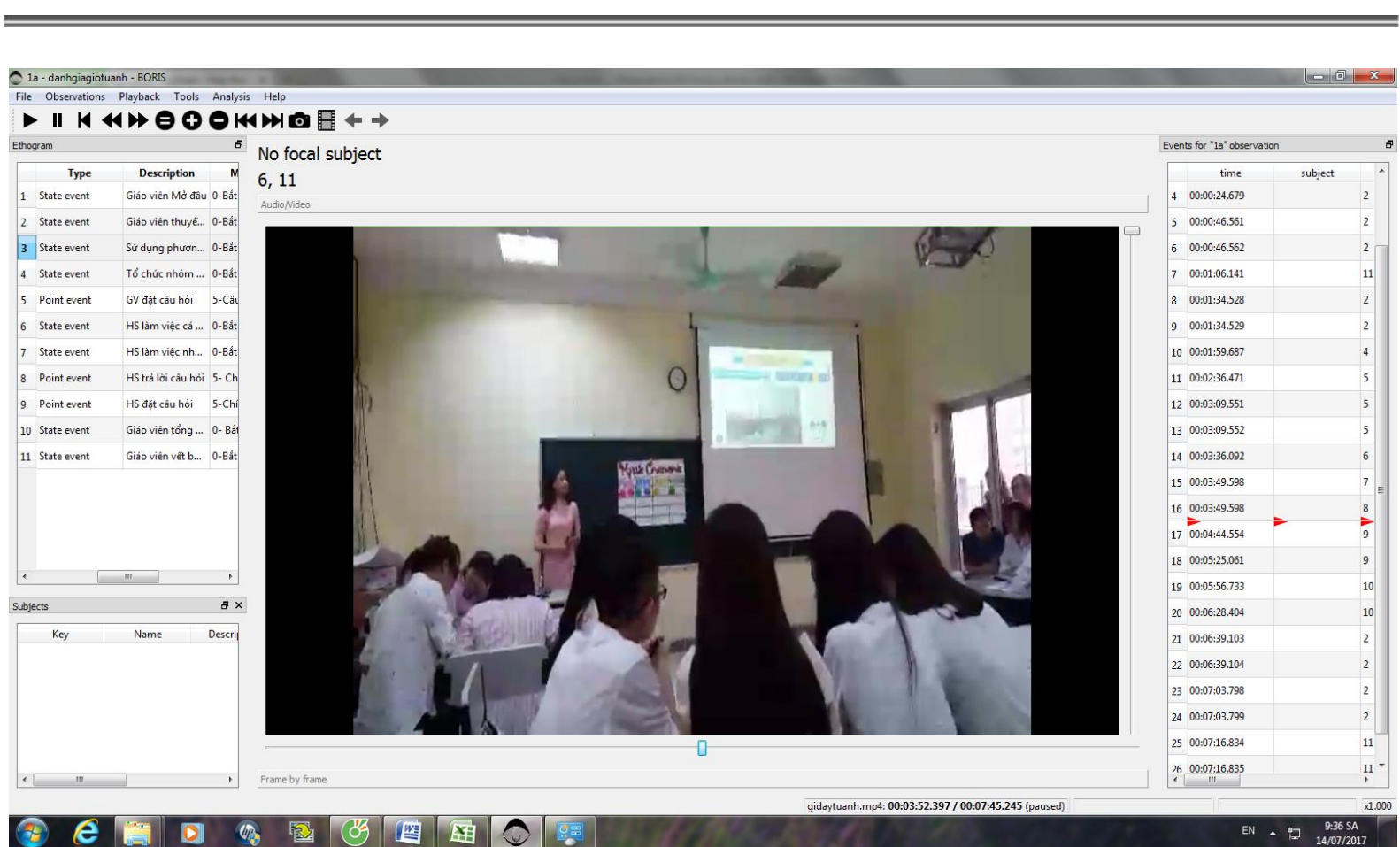

Figure 1. BORIS screen

The work begins with the encoding of video clips, highlight the video on the track by selecting the starting position and end position to determine the range or of the teaching activities, the selected variable or variables point range depending on the purpose of analysis. List of events includes an encoding certain types of information such as the teaching activities, events, actions, gestures of teachers and students. This process can look away, review to avoid shortcomings need to encode video.

After the coding video, the data can export into a table Excel spreadsheet for analysis (Figure 2). 


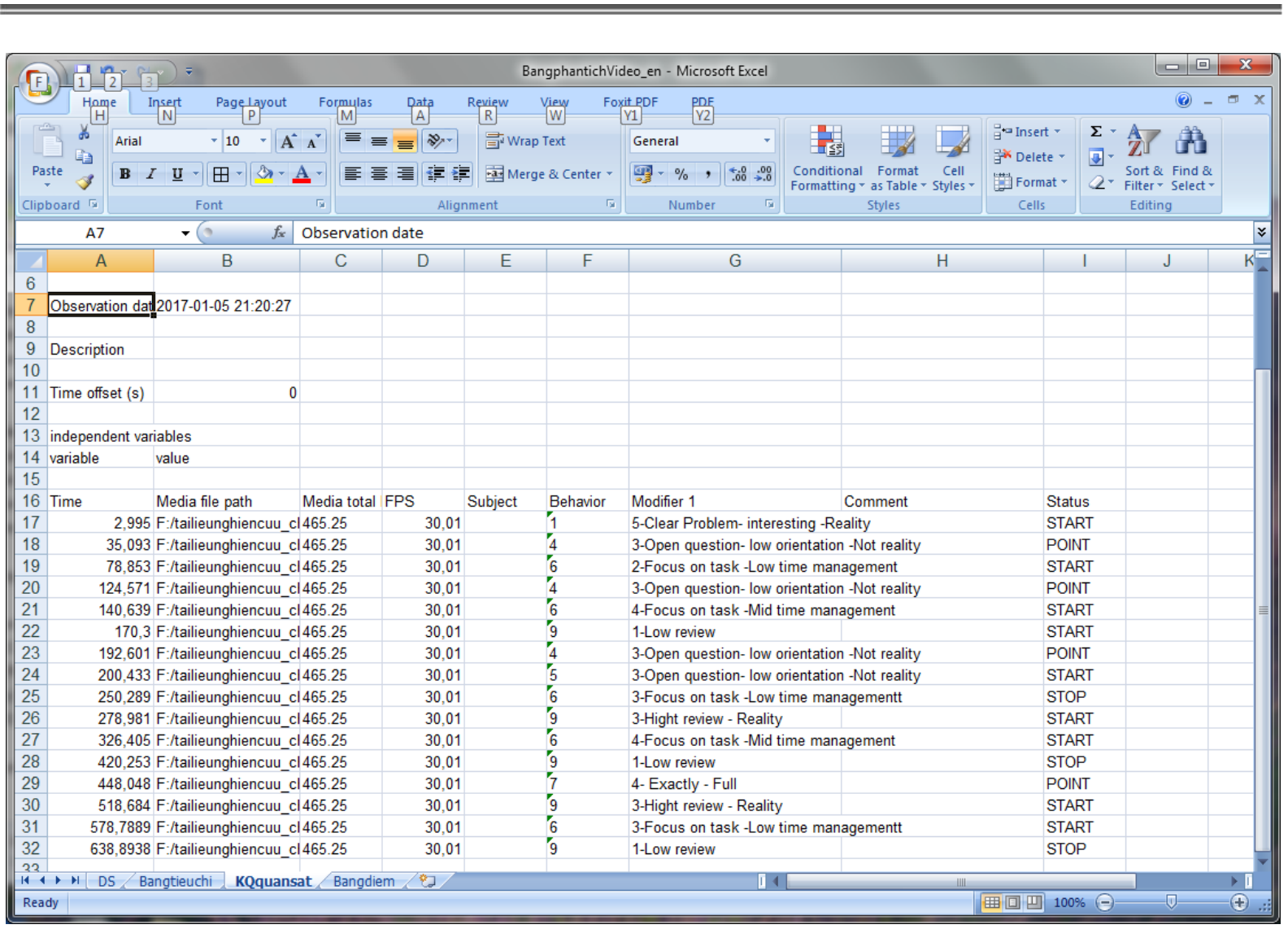

Figure 2.The data of coding video is exported into a tableExcel spreadsheet.

In the process of using BORIS analyzing video of the lesson, we found limitations: The encoding of the events on video according to the levels of encryption and multiple acts simultaneously on software BORIS. These different levels will create too much variables to analyze. We can reduce the difficulty or overcome the mentioned limitations by reducing the number of observations.

\section{Experiment of micro-teaching} with video recording analysis at University of Education, VNU

At the University of Education, VNU, themicro-teaching sessions combined with using BORIS analyzing vid- eo of the student practice teaching are designed to:

- strengthen student approach to teaching;

- identify student teaching skill improvement;

- enhance student understanding for a variety of effective teaching styles; and

- improve student's ability to provide and receive effective feedback.

During micro-teaching session, student will choose a part of lesson, student will prepare lesson plan and teach a lesson for 10-15 minutes and use personal mobile to video recordings, watching the videotape playback on BORIS software, giving feedback 
and listening to the feedback provided by peers (his/her classmates) and teachers.

After the first exercise, student can enhance their teaching: they are encouraged to take some personal time to reflect on the first experienced teaching and can continue to teach the "revised lesson" in 20-30 minutes. Student teacher's reflections do not only focus on what they think, but also on their feelings and ideals (wanting) during the work as Korthagen [6] mentioned in introducing the "realistic approach" in teacher education. Groups of student teachers can be formed and time for sharing in the whole class will be given. During the process of sharing and evaluating, "community of learners" will be created.

In 2016, the study observed practice lessons to be taught by 32sampled Physics student teachers. Every lesson was observed by video recorded. The study then conducted descriptive analyses of score means by observation live and video. The resultanalysis score in 3 times teaching practice at tab 1 and 2 .

Tab. 1

\section{Result Analysis in Microteaching}

\begin{tabular}{llclclcl}
\hline \multirow{2}{*}{ Mark } & \multicolumn{2}{c}{ Time 1 } & \multicolumn{2}{c}{ Time 2 } & \multicolumn{2}{c}{ Time 3 } \\
& Frequency & Percent & Frequency & Percent & Frequency & Percent \\
\hline Valid & 7,5 & 10 & 31,3 & 0 & 0 & 0 & 0 \\
& 8,0 & 5 & 15,6 & 11 & 34,4 & 2 & 6,3 \\
& 8,5 & 12 & 37,5 & 4 & 12,5 & 5 & 15,6 \\
9,0 & 5 & 15,6 & 17 & 53,1 & 21 & 65,6 \\
& 9,5 & 0 & 0 & 0 & 0 & 4 & 12,5 \\
Total & 32 & 100,0 & 32 & 100,0 & 32 & 100,0 \\
\hline
\end{tabular}

Tab. 2

Statistics

\begin{tabular}{|c|c|c|c|}
\hline & \multicolumn{3}{|c|}{ Time 1 Time 2 Time 3} \\
\hline Valid & 32 & 32 & 32 \\
\hline Std. Deviation &, 5499 & ,4655 & ,3617 \\
\hline Variance & ,302 & ,217 &, 131 \\
\hline Minimum & 7,5 & 8,0 & 8,0 \\
\hline Maximum & 9,0 & 9,0 & 9,5 \\
\hline
\end{tabular}

As can be seen from Table 1, there are 4 students who score the maximum points the point 9.5 on the 10 scale at time $3(12,5 \%), 21$ student get the point $9,0(65,6 \%)$, at time 1 is no one get 9,0 and 5 student get 9,0 $(15,6 \%)$. 
It show that students move forward efficiently and enhance their knowledge, skills, abilities.Statisticsa standard deviation of 0,36 at time 3 and 0,54 at time 1 (tab 2) show that teaching skill at time 3 more evenly.

\section{Conclusion}

Micro-teaching provides an opportunity to develop student teacher in teaching skills in which evaluation process via video recording have identified as an important tool to improve the student's teaching skills. As I mentioned from the beginning, to reduce the limitations of teacher training program in Viet Nam in term of time and skill development, Video Analysis tool is a good assessment tool, it can be used to describe almost aspects of the teaching practices and create more opportunities for teacher students to flexibly practice, self-evaluating, sharing and learning from others continuously. To effective applying micro-teaching and BORIS evaluation, however, research on the appropriate conditions and curriculum need to be conducted.

\section{Bibliography}

1. Merrill L. Meehan, Kimberly S. Cowley, Nicole L. Finch, Kristine L. Chadwick, Lisa D. Ermolov, M. Joy S. Riffle (2004). Special Strategies Observation SystemRevised: A Useful Tool for Educational Research and Evaluation, AEL, Institute of Education Sciences (IES), U.S.

2. Klaus R. Scherer and Paul Ekman, Handbook of Methods in Nonverbal Behavior Research, Cambridge University Press, Cambridge, 1982.

3. Megan W. Stuhlman, Bridget K. Hamre, Jason T. Downer, \& Robert C. Pianta (2007) .What Should classroom Observation Measure. Center for Advanced Study of Teaching and Learning (CASTL) / University of Virginia.

4. Pianta, R. C., Hamre, B. K., Haynes, N. J., Mintz, S. L., \& La Paro, K. M. (2007). Classroom assessment scoring system manual, middle/secondary version. Charlottesville: University of Virginia.

5. Sharon J. Derry (2007). Guidelines For Video Research In Education: Recommendations From An Expert Panel. A report from the Data Research and Development Center.http://drdc.uchicago.edu/what/vid eo-research-guidelines.pdf.

6. Korthagen, F. (2010). Situated learning theory and the pedagogy of teacher education: Toward an interactive view of teacher behavior and teacher learning. Teaching and Teacher Education, 26, (p. 98-106).

(c) Pham Kim Ch., 2017. 